\title{
ПОАИТИЧЕСКИЕ РЕЖИМЫ
} И ПОАИТИЧЕСКИЕ ПРОЦЕССЫ

Ямахова Э.Н.

\author{
ПОАИТИЧЕСКОЕ ПРЕАСТАВИТЕАЬСТВО \\ И ПРОБАЕМЫ ОБРАТНОЙ СВЯЗИ В НОВЫХ \\ АЕМОКРАТИЯХ: ОПЫТ ПОСТСОВЕТСКОЙ АИТВЫ
}

\begin{abstract}
Аннотация. Объектом исследования является процесс реализачии политическими партиями своих основных функиий в условиях новых демократий. Особое внимание уделено анализу функиий представительства, селекиии, делегирования и контроля. Взаимодействие между избирателями, политическими партиями, депутатами и правительством рассматривается через аналитические рамки принципал-агентских отношений. Раскрывается ключевая роль в этих отночениях политических партий какглавных принципалов, осуществляющих представительство, селекиию, делегирование и контроль по отночению к кандидатам (агентам) на выборные должности. В качестве эмпирического примера выступает случай постсоветской Аитвы, на материале политического развития которого анализируется степень реализачии политическими партиями своих основных функиий и раскрываются главные проблемы в этом процессе. Аля изучения реализации политическими партиями постсоветской Аитвы функиий представительства, селекции, делегирования и контроля используются теоретические положения теории принципал-агентских отношений, а также методы количественного анализа электоральной статистики. В качестве случаев дяя анализа и сравнения используются данные шести электоральных исходов выборов литовского Сейма, прошедиие в период 1992-2012 гг. Результатом исследования стал вывод о том, что хотя политические

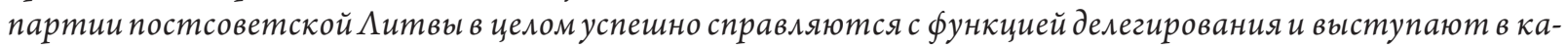
честве главного актора в этом процессе, функиии более высокого порядка в системе принципал-агентских

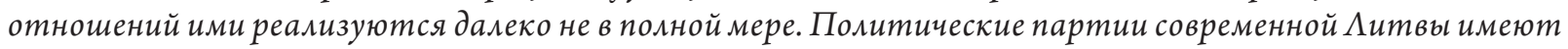
проблемы в плане осуществления контроля за избранными депутатами о чем говорит высокий уровень межпартийной и межфракиионной мобильности депутатского корпуса. Высокий уровень обновления партийных кадров на каждом новом электоральном иикле свидетельствует о попытках решения этой проблемы со стороны партийного руководящего аппарата. Нерешенность вопросов контроля за депутатским корпусом со стороны партий создает ситуачию девальвации доверия к партийным институтам со стороны избирателей, что не способствует процессу институционализации партийной системы и создает риски стабильного функиионирования политической системы.
\end{abstract}

Ключевые слова: демократия, страны Балтии, Аитва, политические партии, политическое представительство, делегирование, электорат, выборы, модернизачия, политика. 
Review. The object of the research is the process of implementation by the political parties of their major functions under the conditions of the new democracies. Particular emphasis is made on the analysis of the functions of representation, selection, delegation and control. Cooperation between the electorate, political parties, lawmakers and the government is examined through the analytical framework of the principal-agent relations. The major role of political parties as principals in this relations is identified, which means they carry out representation, selection, delegation and control towards the candidates (agents) for the elective offices. An empirical example is the case of post-Soviet Lithuania, whose political development provides the material to analyse the degree of implementation of the major functions of the political parties, as well as to define the main issues of this process. In order to examine the implementation by the political parties of post-soviet Lithuania of the representative, selective, delegative and controlling functions, the theory of the principal-agent relations has been used, as well as methods of quantitative analysis of the electoral statistics. The data of six electoral results of elections to the Lithuanian Seimas from 1992 to 2012 has been used for analysis and comparison. The research has resulted in the conclusion that although the political parties of post-soviet Lithuania, in general, successfully deal with the function of delegation and act as the main actor in this process, they do not fully implement higher functions in the system of principal-agent relations. The political parties of modern Lithuania have problems regarding the control over selected lawmwkers, which is evidenced by the high level of inter-party and interfaction mobility of the deputy corps. The high level of renewal of the party's cadres during every electoral cycle witnesses the attempts to solve this problem by the party apparatus. Uncertainty of the issues of control over the deputy corps on the part of the parties creates the situation of devalvation of trust towards the party institutions on the part of the electorate, which does not contribute to the process of implementation of the party system, and creates risks for the sustainable functioning of the political system.

Keywords: electorate, political delegation, political representation, political parties, Lithuania, the Baltic countries, democracy, elections, modernisation, policy.

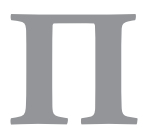
омитические партии в современных обществах явмяются важнейшими посреАниками межАу избиратемями и властью. В условиях Аемократии партии осуществмяют важную функцию Аелегирования полномочий. Встроенные в политико-властную иерархию, партии агрегируют мимкионы голосов избирателей, отАанных за конкретных политиков, занимающих по результатам выборов вцастные позиции. В этом процессе трансформации голосов в Аепутатские места и Аругие государственные Аолжности политические партии выполняют центрацьную роль Аемократического Аелегирования.

В социальной и экономической жизни процесс Аелегирования полномочий происходит Аостаточно часто. Сфера политики в этом смысле не явцяется искиючением. Поэтому экономический поАхоА, основанный на анализе делегирования как принципа ется вполне проАуктивным Аля исслеАований анамогичного феномена в политической жизни. Согласно кмассическому экономическому опредецению Аелегирование понимается как ситуация, при которой оАин субъект (принципац) вступает в отношения с Аругим субъектом (агентом) с це$\Lambda$ ью обмена полномочиями Аля решения опреАе-

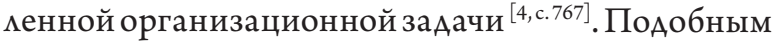
образом в политической жизни Аелегирование характеризуется процессом, при котором субъекты власти передают права принятия решений иным субъектам ${ }^{[11, \text { с. 266] }}$. Отношения Аемегирования, основанные на принципал-агентских сетях, в условияхпреАставительной и парламентской Аемократии связывают воеАино избирателей, Аепутатов законодатемьных ассамблей, правительственные министерства и государственный аппарат в еАиную политическую систему. Таким образом, можно выдекит четыре уровня парламентской Аемократии, в рамках которой Аелегирование осуществляет взаимосвязь разных эмементов: 1) связь избирателей (принципалов) с Аепутатами законодательных собраний (агентами); 2) связь Аепутатов законодательных собраний (принципалов) с министрами исполнительной власти (агентами); 3) связь министров (принципалов) с главами размичных Аепартаментов и комитетов (агентами); 4) связь глав департаментов и комитетов (принципалов) с госуАарственными служащими среАнего и нижнего звена (агентами).

ОчевиАно, что кажАый из субъектов может оАновременно выступать и в роли принципала, и в роли агента, в зависимости от уровня и направленности процесса Аелегирования. Вместе с тем, на практике в рамках парламентской Аемократии политические партии в процессе Аемегирования играют более значительную и Ааже Аоминирующую роль в сравнении с Аругими субъектами. Происходит это потому, что помитические партии вступают в процесс Аелегирования не на оАном этапе в рамках преАставленной выше 
Таблииа 1. Количество независимых кандидатов, баллотирующихся и избранных на парламентских выборах Литвы (1992-2012 г2.)

\begin{tabular}{|l|l|l|l|l|}
\hline Год & $\begin{array}{l}\text { Общее } \\
\text { число кандидатов }\end{array}$ & $\begin{array}{l}\text { Независимые } \\
\text { кандидаты }\end{array}$ & $\begin{array}{l}\text { Общее число } \\
\text { депутатских мест }\end{array}$ & $\begin{array}{l}\text { Количество неза- } \\
\text { висимых депутатов }\end{array}$ \\
\hline 1992 & 472 & $33(7 \%)$ & 141 & $1(1 \%)$ \\
\hline 1996 & 879 & $31(4 \%)$ & 137 & $4(3 \%)$ \\
\hline 2000 & 702 & $48(7 \%)$ & 141 & $3(2 \%)$ \\
\hline 2004 & 1800 & $57(3 \%)$ & 141 & $6(4 \%)$ \\
\hline 2008 & 1200 & $65(5 \%)$ & 141 & $4(3 \%)$ \\
\hline 2012 & 1900 & $75(4 \%)$ & 139 & $3(2 \%)$ \\
\hline
\end{tabular}

Источник: Офиицальный сайт Центральной избирательной комиссии Литвы. [Электронный документ]: режим доступа: // http://www.vrk.lt/en/ (дата обращения: 18.06.2014).

теоретической схемы, но на кажАом из четырех уровней.

Так, хотя формамьно избирате и прямо выбирают Аепутатов, в Аействитемьности именно партии произвоАят их отбор и номинацию. В ходе общенациональных выборов избиратели реАко знаю точно конкретных персон, которые вкцючаются в партийный избиратемьный $и$ ит. Фактически, отАавая свой голос за конкретного кандиАата, избиратели на самом деле голосуют за партию ${ }^{[1]}$.

Кроме того, как следует из теории, устойчивость принципал-агентских отношений зависит от способности принципама осуществцять контроль наА агентом. Это контроль возможен при наличии Авух условий: 1) обязатемьств агента Аействовать только в рамках Аоговоренностей с принципалом и 2) накичия упринципала реальных механизмов поощрения и наказания агентов в зависимости от исполнения этих обязательств ${ }^{[11, c .267]}$. Если посмотреть на отношения межАу избиратемями и избранными Аепутатами с точки зрения контромя первых (как принципамов) наА вторыми (как агентов), то обнаруживается, что куаа более тесный контроль и, следовательно, реальные функции принципалов имеют именно партии, а не избиратеки ${ }^{[7, \text { с.311] }}$.

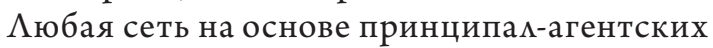
связей имеет проблему выхода из-под контроля агентов, которые могут иметь свои собственные интересы, выходящие за рамки обязательств по отношению к принципалу ${ }^{[10]}$. Подобно как бизнес-структурах акционеры (принципамы) не всегАа могут контролировать менеАжеров преАприятия (агентов), в политике избиратели имеют весьма ограниченный набор механизмов, способныхим контролировать уже избранных Аепутатов. Куаа большие ресурсы контроля имеют в своем распоряжении номинировавшие депута- тов политические партии. В отмичие от избиратемей, которые выпомняют функцию принципама только в периоА выборов, политические партии контактируют с Аепутатами на регулярной основе в стенах законодательного органа, что позволяет им постоянно отслеживать исполнение обязательств избранных политиков. При этом, в отличие от избирателей, политические партии могут закмючить формахьные и достаточно четкие Аоговоренности относитемьно партийной Аисциплины, что позвоцяет партиям не только отслеживать Аеятельность своих номинантов, но и наказывать их в случае нарушения ими ого-

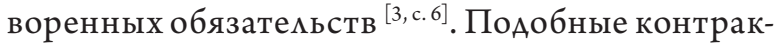
ты отвечают интересам партий, поскомьку они заинтересованы в Аолгосрочном политическом существовании и расширении своей экекторацьной базы. Этого невозможно Аостигнуть в случае, если партия не может гарантировать своим избирателям контроль наА змоупотреблениями своих выАвиженцев. Поэтомупринципы партийной Аисциплины стали достаточно распространенными практиками функционирования пармаментской Аемократии ${ }^{[9]}$. ОАнако, этот же факт позволяет утвержАать, что в реацьности именно политические партии, а не избиратели, выполняют главные функции принципалов по отношению к Аепутатам (агентам).

Исследования европейской политики показывают, что помитические партии в парламентских Аемократиях остаются главными посреАниками в процессе замещения Аепутатских мест в законодательных собраниях. Значительное меньшинство политиков бамлотируется на выборах как независимые кандилаты и стараются выиграть электорамьные баталии без поААержки партий. Еще меньше тех, комуУАается это сАелать вне партийного чменства ${ }^{[8 ; 5]}$. Эти вывоАы в цемом 
Таблииа 2. Межпартийная мобильность депутатов Сейма Литвы первого созыва (1992-1996 г2.)

\begin{tabular}{|l|l|l|l|l|}
\hline & ДПТЛ & СДПЛ & СО (ЛК) & ХДП \\
\hline 1992 & 74 & 7 & - & 10 \\
\hline 1993 & 73 & 7 & - & 10 \\
\hline 1994 & 72 & 7 & 23 & 12 \\
\hline 1995 & 70 & 7 & 23 & 12 \\
\hline 1996 & 60 & 7 & 24 & 12 \\
\hline Мобильность всего & -14 & 0 & +1 & +2 \\
\hline Мобильность в\% & $19 \%$ & $0 \%$ & $4 \%$ & $20 \%$ \\
\hline
\end{tabular}

Источник: Žvaliauskas G. Application of Ex ante measures in political delegation: The case of Lithuania // Journal of Baltic Studies. 2004. № 3. P. 264.

согласуются с эмпирическими Аанными политического развития постсоветской $\Lambda$ итвы.

Хотя избирательное законодательство Аитвы позволяет бамлотироваться в законодательное собрание независимым кандидатам, Аля чего они Аолжны собрать не менее чем 1000 поАписей гражАан ${ }^{[6]}$, тем не менее Аоля непартийных кандиАатов в течении постсоветских выборов крайне невелика. Так же совсем минимацьно количество успешно избранных независимых кандидатов (см. Таб. 1).

В ходе шести электорамьных цикмов Аитвы, прошеАших в периоА 1992-2012 гг., из 6953 номинированных кандиАатов только 309 участвова ии в выборахв качестве независимых, что составцяет 4,4\%. Всего 21 из них можно отнести к историям успеха, то есть только 21 независимых кандиАатов в период 1992-2012 гг. стаци депутатами парламента, что состав яет мишь 2,5\% от общего количества Аепутатов, избранных в этот периоА.

Как виАно из преАставленных Аанных, максимальное число независимых кандидатов $(\mathrm{N}=6)$, избранных в законодательное собрание, бымо в 2004 г. и составимо 4\% от всего Аепутатского корпуса. ОАнако Ааже этих Аепутатов можно отнести к независимым весьма условно, поскольку на практике уже после избрания они, как правимо, вступали в какую-либо партийную фракцию ${ }^{[12]}$.

Таким образом, помитические партии $\Lambda$ итвы, несмотря на сравнительно небольшую историю своего развития, стали кмючевыми посреАниками в обеспечении канамов доступа кандидатам к властным позициям. В этом смысле они вполне эффективно выполняют функцию Аелегирования и могут рассматриваться как принципамы, контролирующие номинацию и семекцию агентов. ОАнако, наскомько хорошо эти функции реамизуются на бомее высоких уровнях принципа - агентских отношений? В частности, насколько эффективно партии способны установить контроль за повеАением избранных кандиАатов и слеАить за нормами партийной Аисциплины?

Ответить на эти вопросы можно с помощью анамиза межпартийной и межфракционной мобимьности Аепутатов законодательного органа вмасти. Можно преАположить, что низкая межпартийная мобимьность может служить признаком высокой партийной Аисциплины, в то время как высокий уровень этого параметра позволяет сАелать противоположное утвержАение.

Аанные постсоветского партийного развития $\Lambda$ итвы Аемонстрируют, что в отмичие от уровня выборов, на которых партии эффективны с точки зрения реацизации функции Аелегирования, контроль за парламентской Аисциплиной партиям УАается обеспечить очень реАко. Все наибо-

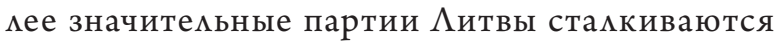
с проблемой дезертирства Аепутатов, которые переходят в Аругие партийные проекты или пармаментские фракции Аовольно часто. Ситуации высокой межпартийной мобимьности Аепутатов и Ааже расколов фракций является Аля политического процесса постсоветской $\Lambda$ итвы достаточно привычным явмением.

При этом Аанные показывают, что наибольшие проблемы с партийной Аисциплиной наблюАаются У тех партий, которые преАставцяют большинство и контролируют правительство. Вероятно, разногласия по конкретным вопросам реализации политического курса в большей мере способствуют непреодолимым конфликтам внутри партийных фракций, слеАствием чего явмяется бегство Аепутатов в Аругие фракции. Оппозиционные фракции, как правило, сохраняют стабимьность. Если относитемьно них и можно говорить о межпартийной мобимьности, то она 
Таблица 3. Межпартийная мобильность депутатов Сейма первого созыва (1996-2000 г2.)

\begin{tabular}{|l|l|l|l|l|l|l|}
\hline & ДПТЛ & СДПЛ & СО (ЛК) & ХДП & ЛЦС & ЛЛС \\
\hline 1996 & 12 & 12 & 70 & 16 & 14 & 3 \\
\hline 1997 & 12 & 12 & 70 & 16 & 15 & 3 \\
\hline 1998 & 13 & 11 & 67 & 16 & 16 & - \\
\hline 2000 & 13 & 7 & 65 & 12 & 18 & - \\
\hline Мобильность всего & +1 & 7 & 49 & 12 & 17 & - \\
\hline Мобильность В\% & $8 \%$ & $42 \%$ & -21 & -4 & +3 & -3 \\
\hline
\end{tabular}

Источник: Žvaliauskas G. Application of Ex ante measures in political delegation: The case of Lithuania // Journal of Baltic Studies. 2004. № 3. P. 264.

Таблиия 4. Межпартийная мобильность депутатов Сейма первого созыва (2000-2004 гг.)

\begin{tabular}{|l|l|l|l|l|}
\hline & СДПЛ & СО (ЛК) & ЛЛС & HС \\
\hline 2000 & 48 & 9 & 34 & 29 \\
\hline 2001 & 49 & 9 & 34 & 26 \\
\hline 2002 & 50 & 9 & 23 & 26 \\
\hline 2003 & 53 & 9 & 27 & 26 \\
\hline 2004 & 52 & 10 & 21 & 22 \\
\hline Мобильность всего & +4 & +1 & -13 & -7 \\
\hline Мобильность в\% & $8 \%$ & $11 \%$ & $38 \%$ & $24 \%$ \\
\hline
\end{tabular}

Источник: Žvaliauskas G. Application of Ex ante measures in political delegation: The case of Lithuania // Journal of Baltic Studies. 2004. № 3. P. 264.

имеет положительную Аинамику. Низкий уровень межпартийной мобимьности оппозиционных игроков, вероятно, связан с консолидацией Аепутатов против партии большинства на основе негативного консенсуса. Сам оппозиционный статус формирует больше стимулов Аля решения проблемы комиективного Аействия ${ }^{[2]}$ и уАерживает депутатов от стратегии Аезертирства и раскола фракций.

Так, победившая на парламентских выборах 1992 г. «Аемократическая партия труАящихся Аитвы» (АПТА $)$ к 1996 г. сократила свою фракцию с 74 членов Ао 60, что составляет 19\%. Все Аругие партии, которые находимись в магере оппозиции, избежаки проблемы выхода из их рядов Аепутатов. Наоборот, «Союз Отечества - Аитовские Консерваторы» (СО $(\Lambda К))$ в период с 1994 по 1996 гг. увеличими свою фракцию на оАного Аепутата, а фракция «Христианско-демократической партии» (ХАП) попомнимась Авумя Аепутатами и возросла с 10 Ао 12 членов (См. Таб. 2).

В $и$ иовском Сейме созыва 1996-2000 гг. также наблюдалась наиболее высокая межпартийная мобильность у фракций инкумбента, в то время как оппозиционные фракции Аемонстрироваци довоцьно высокую стабильность (см. Таб.
3). Фракция партии «Аемократическая партия труАящихся $\Lambda$ итвы» (АПТ $\Lambda)$, которая по результатам выборов на этот раз оказацась в меньшинстве и перешиа в оппозицию, весь срок созыва парламента сохранима свою численность и даже увекичима ее с 12 до 13 чменов. Новая оппозиционная фракция «Аитовский Центристский Союз» (АЦС) также в период работы преАставительного органа увеличима свою фракцию на $21 \%$ с 14 ао 17 чменов.

Напротив, все партии увмасти продемонстрировали негативную Аинамику в межпартийной мобимьности. Так, фракция «ХристианскоАемократической партии» (ХАП) сократилась на 25\% с 16 до 12 Аепутатов. Правящая фракция «Социа -Аемократической партии $\Lambda$ итвы» (САП $\Lambda$ ) сократимась на 42\%, сократившись с 12 Ао 7 Аепутатов. Наиболее многочисленная фракция правящей партии «Союз Отечества» сократилась на $30 \%$ с 70 Ао 49 чменов. Еще одна немногочисленная, но входящая в правящую коаиицию фракция партии « Иитовский $\Lambda$ иерамьный Союз» $(\Lambda \Lambda Ю)$, вовсе прекратика свое существование к 1998 г.

Ситуация с межпартийной мобимьностью в рамках митовского парламента созыва 2000- 
Таблииа 5. Соотношение старых и новых партийных кадров на выборах литовского Сейма 1996 г.

\begin{tabular}{|l|l|l|l|}
\hline Партии & Старые кадры & Новые кадры & Всего \\
\hline ДПТЛ & $45(43 \%)$ & $60(57 \%)$ & $105(100 \%)$ \\
\hline СДПЛ & $22(23 \%)$ & $75(77 \%)$ & $97(100 \%)$ \\
\hline СО (ЛК) & - & - & - \\
\hline ХДП & $15(17 \%)$ & $71(83 \%)$ & $86(100 \%)$ \\
\hline ЛЦС & $13(16 \%)$ & $68(84 \%)$ & $81(100 \%)$ \\
\hline ЛЛС & $6(15 \%)$ & $35(85 \%)$ & $41(100 \%)$ \\
\hline
\end{tabular}

Источник: Официальный сайт Центральной избирательной комиссии Литвы. [Электронный документ]: режим доступа: // http://www.vrk.lt/en/ (дата обращения: 18.06.2014).

Таблииа 6. Соотношение старых и новых партийных кадров на выборах литовского Сейма 2000 г.

\begin{tabular}{|l|l|l|l|}
\hline Партии & Старые кадры & Новые кадры & Всего \\
\hline ДПТЛ & $36(62 \%)$ & $22(38 \%)$ & $58(100 \%)$ \\
\hline СДПЛ & $23(43 \%)$ & $31(57 \%)$ & $54(100 \%)$ \\
\hline СО (ЛК) & $45(40 \%)$ & $68(60 \%)$ & $113(100 \%)$ \\
\hline ХДП & $27(42 \%)$ & $37(58 \%)$ & $64(100 \%)$ \\
\hline ЛЦС & $27(28 \%)$ & $70(72 \%)$ & $97(100 \%)$ \\
\hline ЛЛС & $13(10 \%)$ & $117(90 \%)$ & $130(100 \%)$ \\
\hline
\end{tabular}

Источник: Официальньй сайт Центральной избирательной комиссии Литвы. [Электронный документ]: режим доступа: // http://www.vrk.lt/en/ (дата обращения: 18.06.2014).

2004 гг. наблюдается искмючение из общего правима сокращения фракций партий-инкумбентов в виде «Социа -демократической партии $\Lambda$ итвы» (САП $\Lambda)$, которая буАучи у власти смогма не только не сократить свою фракцию, но увеличить ее на $8 \%$. С 48 членов в 2000 г. она возросла к 2004 г. Ао 52 Аепутатов (см. Таб. 4).

ОАнако в случаях с Аругими фракциями наблюдается прежняя закономерность: оппозиционные партии имеют более низкую межпартийную мобимьность в сравнении с фракциями, контролирующими министерские правительственные должности. Так, фракция «Аитовского $\Lambda$ иберамьного Союза $(\Lambda \Lambda \mathrm{C})$, входящей в коа иционное правитецьство, сократимась на $13 \%$, с 34 Ао 21 Аепутата. Равным образом правящая фракция «Новый Союз» (НС) сократилась на 24\% с 29 Ао 22 членов. Напротив, оппозиционная фракция «Союз Отечества» (СО) увекичима свое количество на оАного АеПутата.

В целом преАставленный анамиз межпартийной мобимьности в трехпервых созывах $и$ иовского парламента позвоцяет слелать вывоА, что $и$ итовские партии, наряду с эффективной реализацией функции Аелегирования политических каАров, не облаАают столь же симьными возможностями осуществлять партийную Аисциплину. Аоказательством этому служит высокий уровень межпартийной мобимьности у правящих партий. Таким образом, на уровне пармаментских фракций партии теряют свое кмючевое значение в сфере контроля Аелегирования полномочий.

ОАним из способов увемичить партийную Аисциплину явмяется обновление партийных каАров. Искиючение из партийных списков нарушителей партийных обязатемьств и рекрутация новых каАров можно признать оАним из эффективных способов восстановления контроля партийного руководства как принципалов за агента-

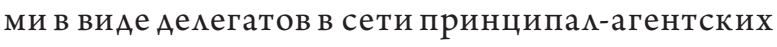
отношений. Существующие Аанные о степени обновления партийных кадров на выборах пар-

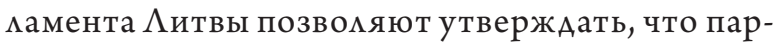
тийное руководство понимает это и осуществмяет именно такую стратегию. Аействитемьно, Аанные свидетельствуют, что с кажАым электоральным циклом политические партии Аитвы существенно обновмяют минейку своего калрового состава, выставцяемого в избиратемьные партийные списки.

Так, все партии, участвовавшие вторично на выборах Сейма в 1996 г. очень существенно 
обновили свои кадры в сравнении с выборами 1992 г. (см. Таб. 5).

Как видно из преАставленных Аанных, Аоля обновления у всехпартий составила от 57\% Ао $85 \%$. На выборах 2000 г. этот показатель у большинства партий стал значительно ниже (см. Таб. 6).

Например, у «Аемократической партии труАящихся $\Lambda$ итвы» (АПТ $\Lambda)$ обновление каАров сократилось с 57\% в 1996 г. Ао 38\% в 2000 г. «Социац-Аемократическая партия $\Lambda$ итвы» (САП $\Lambda)$ сократила в тот же период обновление каАров с $77 \%$ Ао 57\%. «Христианско-демократическая партия» (ХАП) сократима обновмение партийных каАров с $83 \%$ в 1996 Ао $58 \%$ в 2000 г. Партия « Аитовский Центристский Союз» понизим обновмение партийных списков с 84\% в 1996 г. до 72\% в 2000 г. Искмючением выступает только партия « $\Lambda$ итов-

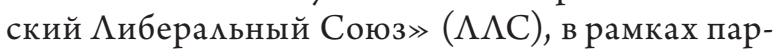
тийных списков которой наблюАается повышение обновления каАрового состава в тот же период c $85 \%$ A $90 \%$.

Представленные Аанные и анализ реализации функций Аелегирования, семекции и контроля партийных каАров политическими партиями Аитвы позволяет сделать следующие основные выводы.

Новые Аемократии сталкиваются с рядом специфических проблем, связанных с относительно неАавним происхожАением основных демократических институтов и незавершенностью процесса их институционализации. Ихотя поАитические партии стали кАючевыми игроками

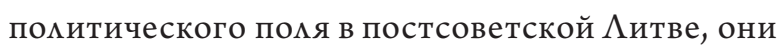
Ао сих пор не в силах выполнять весь комплекс функций главных посреАников межАу обществом и властью.

Исследование роли партий, осуществленное на основе принципа $\Lambda$-агентского поАхода, выяви$\Lambda 0$, что хотя политические партии постсоветской $\Lambda$ итвы в целом успешно справ яются с функцией Аемегирования и выступают в качестве главного актора в этом процессе, функции более высокого порядка в системе принципа - -агентских отношений ими реализуются Аалеко не в полной мере.

Политические партии современной $\Lambda$ итвы имеют проблемы в плане осуществления контроля за избранными Аепутатами о чем говорит высокий уровень межпартийной и межфракционной мобильности Аепутатского корпуса. Высокийуровень обновмения партийных каАров на кажАом новом электоральном цикле свидетельствует о попытках решения этой пробцемы со стороны партийного руководящего аппарата.

Есть все основания преАположить, что в Аальнейшем может сыграть фактор времени и долговременность функционирования партийной системы Иитвы приведет к решению обозначенных пробцем. Пока же нерешенность вопросов контроля за Аепутатским корпусом со стороны партий создает ситуацию Аевальвации доверия к партийным институтам со стороны избирателей, что не способствует процессу институционализации партийной системы и созАает риски стабильного функционирования политической системы.

\section{БИБАИОГРАФИЯ}

1. Курлов А.Б., Суханов В.К., Шкель С.Н. Социодинамика политических приоритетов эмектората в условиях регионацьного самоуправления. Уфа: РИО БашГУ, 2003. 232 с.

2. ОАсон М. Аогика комлективных действий: общественные блага и теория групп. М.: ФонА экономической инициативы, 1995.174 с.

3. Bowler S., Farrell D., Katz R. Party Cohesion, Party Discipline, and Parliaments // Party Discipline and Parliamentary Government. Columbus: Ohio State University Press, 1999. P. 3-22.

4. Dahlstroma R., Ingramb R. Social Networks and the Adverse Selection Problem in Agency Relationships // Journal of Business Research. 2003. № 56. P. 767-775.

5. Gallagher M., Laver M., Mair P. Representative Government in Modern Europe. London: McGraw-Hill, 2001.287 p.

6. Law on Election to the Seimas. 9 July 1992 No. I-2721. Vilnius (New edition as 18 July 2000, No. VIII-1870) (As amended by 23 August 2004, No. IX-2429)12 October 2003. [Электронный Аокумент]: режим Аоступа: http://www.legislationline.org/documents/action/popup/id/4858 (Аата обращения: 11.02.2015).

7. Miiller W.C. Political Parties in Parliamentary Democracies: Making Delegation and Accountability Work // European Journal of Political Research. 2000. № 37. P. 309-333.

8. Ranney A. Candidate Selection // Democracy at the Polls: Comparative Study of Competitive National Elections. Washington, DC: American Enterprise Institute for Public Policy Research, 1981. P. 75-105.

9. Sartori G. Comparative Constitutional Engineering: An Inquiry into Structures, Incentives and Outcomes. New York: Macmillan, 1994. 231 p. 
10. Selden S. C., Brewer G. A., Brudney J.L. The Role of City Managers. Are They Principals, Agents, or Both? // American Review of Public Administration. 1999. № 2. P. 124-148.

11. Strom K. Delegation and Accountability in Parliamentary Democracies // European Journal of Political Research. 2000. № 37. P. 261-289.

12. Žvaliauskas G. Application of Ex ante measures in political delegation: The case of Lithuania // Journal of Baltic Studies. 2004. № 3. P. 254-277.

13. Ямалова Э.Н. Национализм стран Балтии в сравнительной перспективе // Политика и Общество. - 2015.— 1.—C. 24-29. DOI: 10.7256/1812-8696.2015.1.14086.

14. А.В. Манойло Политическая модернизация системы международных отношений и российская модель информационно- психологического управления конфликтами // Психология и Психотехника. - 2011.- 7.- С. 130-137.

\section{REFERENCES (TRANSLITERATED)}

1. Kurlov A. B., Sukhanov V.K., Shkel' S. N. Sotsiodinamika politicheskikh prioritetov elektorata v usloviyakh regional'nogo samoupravleniya. Ufa: RIO BashGU, 2003. $232 \mathrm{~s}$.

2. Olson M. Logika kollektivnykh deistvii: obshchestvennye blaga i teoriya grupp. M.: Fond ekonomicheskoi initsiativy, 1995. $174 \mathrm{~s}$.

3. Bowler S., Farrell D., Katz R. Party Cohesion, Party Discipline, and Parliaments // Party Discipline and Parliamentary Government. Columbus: Ohio State University Press, 1999. P. 3-22.

4. Dahlstroma R., Ingramb R. Social Networks and the Adverse Selection Problem in Agency Relationships // Journal of Business Research. 2003. № 56. P. 767-775.

5. Gallagher M., Laver M., Mair P. Representative Government in Modern Europe. London: McGraw-Hill, $2001.287 \mathrm{p}$.

6. Law on Election to the Seimas. 9 July 1992 No. I-2721. Vilnius (New edition as 18 July 2000, No. VIII-1870) (As amended by 23 August 2004, No. IX-2429)12 October 2003. [Elektronnyi dokument]: rezhim dostupa: http://www.legislationline.org/documents/action/popup/id/4858 (data obrashcheniya: 11.02.2015).

7. Miiller W.C. Political Parties in Parliamentary Democracies: Making Delegation and Accountability Work // European Journal of Political Research. 2000. № 37. P. 309-333.

8. Ranney A. Candidate Selection // Democracy at the Polls: Comparative Study of Competitive National Elections. Washington, DC: American Enterprise Institute for Public Policy Research, 1981. P. 75-105.

9. Sartori G. Comparative Constitutional Engineering: An Inquiry into Structures, Incentives and Outcomes. New York: Macmillan, 1994. $231 \mathrm{p}$.

10. Selden S. C., Brewer G. A., Brudney J. L. The Role of City Managers. Are They Principals, Agents, or Both? // American Review of Public Administration. 1999. № 2. P. 124-148.

11. Strom K. Delegation and Accountability in Parliamentary Democracies // European Journal of Political Research. 2000. № 37. P. 261-289.

12. Žvaliauskas G. Application of Ex ante measures in political delegation: The case of Lithuania // Journal of Baltic Studies. 2004. № 3. P. 254-277.

13. Yamalova E. N. Natsionalizm stran Baltii v sravnitel'noi perspektive // Politika i Obshchestvo._ 2015._1.- C. 24-29. DOI: 10.7256/1812-8696.2015.1.14086.

14. A.V. Manoilo Politicheskaya modernizatsiya sistemy mezhdunarodnykh otnoshenii i rossiiskaya model' informatsionno- psikhologicheskogo upravleniya konfliktami // Psikhologiya i Psikhotekhnika._-2011._ 7.- C. $130-137$. 